\section{Graft rejection}

Significant steps are being made in unravelling the naturally complex mechanisms that keep the anterior segment free from sight-threatening inflammatory responses. Anterior chamber associated immune deviation (ACAID) has been recognised for some time to be involved. ${ }^{1}$ It now appears that the ability of certain cell surface receptors such as Fas ligand are important in dictating how host lymphocytes respond to donor tissue. ${ }^{2}$ These mechanisms may well have evolved largely to deal with trauma and infection, but clearly play their part in the recipient eye's demonstration of relative immune privilege when challenged by an allograft.

There are a number of opportunities between corneal donation and a successful outcome that are available to further reduce the risk of corneal graft rejection. The ability to store corneas for up to 1 month does provide for planned surgery such that donor tissue adheres to high minimum standards and the recipient eye is as quiescent as possible. Organ culture also provides ample time to facilitate appropriate HLA tissue matching. Sustained efforts have been made to arrive at a consensus on the value of matching and its effectiveness. ${ }^{3}$ Prospective studies on Class I and Class II matching using improved laboratory methods for tissue typing are under way in Germany, and are planned to start shortly in the UK. Finally, the evaluation of deep lamellar keratoplasty may further reduce the likelihood of threat to donor tissue from rejection. ${ }^{4}$

Despite this, large actuarial analyses of outcome in penetrating keratoplasty consistently show that immunological rejection is the principal cause of graft failure. ${ }^{5-8}$ The likelihood of rejection is largely dictated by host factors, in particular previous graft failure and stromal vascularisation. Even in low-risk situations rejection cannot be guaranteed not to occur, and there will always be the need for patient education, careful observation, prophylaxis and aggressive treatment of rejection episodes.

Opinions vary considerably on the relative merits of prophylaxis and for just how long patients should use drops, but the last opportunity to prevent failure from immunological rejection and maintain a clear cornea is when a rejection episode becomes manifest. Once rejection is recognised, itself an important part of post-operative management, treatment when instituted early enough can save the day. No one disputes the value of intensive topical steroids, particularly prednisolone acetate which penetrates the eye so well. ${ }^{9}$ However, some ophthalmologists will fight shy of systemic treatment with oral and intravenous steroids, and will be inhibited by new drugs and concerns about the systemic effects in patients where the fellow eye may be normal.

It is thus encouraging to find a preliminary report by Lam et al. ${ }^{10}$ in this issue of Eye that suggests a combination of low-dose oral cyclosporin and a single intravenous pulse of steroids is particularly effective in treating rejection episodes. Although these results are promising, the authors cautiously conclude that only when randomised prospective studies have been carried out can any firm recommendations be made. This necessity is likely to involve multicentre studies, which are complex to design and laborious to instigate because of the necessity for repeated Ethics Committee approval, their cost and the problems of capture of long-term follow-up data.

Nevertheless the involvement of several centres and substantial numbers of patients would have the beneficial effect of widening the debate and making more likely the implementation of recommendations as and when these are made. Information that could be gained en passant might include whether inpatient versus outpatient treatment of rejection is appropriate. An additional advantage would be to concentrate clinicians' minds on what is an acceptable control group, and what particular post-operative regime should be used for such patients.

\section{References}

1. Sonoda Y, Streilein JW. Impaired cell-mediated immunity in mice bearing healthy orthotopic corneal grafts. J Immunol 1993;150:1727-54.

2. Stuart PM, Griffiths TJ, Usui N, Pepose J, Yux H, Ferguson TA. CD95 ligand (Fas ligand) induced apoptosis is necessary for corneal allograft survival. J Clin Invest 1997;99:396-402.

3. Gore SM, Vail A, Bradley BA, Rogers CA, Easty DL, Armitage WJ. HLA-DR matching in corneal transplantation: systematic review of published evidence. Transplantation 1995;60:1033-9.

4. Sugita J, Kondo J. The removal of pathological stroma for vision improvement. Br J Ophthalmol 1997;81:184-8.
Mr A.B. Tullo, MD,

FRCOphth

Manchester Royal Eye

Hospital

Oxford Road

Manchester M13 9WH, UK

Fax: $+44(0) 1612726618$ 
5. Williams KA, Muehlberg SM, Lewis RF, Coster DJ. How successful is corneal transplantation? A report from the Australian Corneal Graft Register. Eye 1995;9:219-27.

6. Vail A, Gore SM, Bradley BA, Easty DL, Rogers CA Armitage WJ. Clinical and surgical factors influencing corneal graft survival, visual acuity and astigmatism. Ophthalmology 1996;103:41-9.

7. Boisjoly HM, Roy R, Bernard PM, Dube I, Laughrea PA, Bazin R. Association between corneal allograft reactions and HLA compatibility. Ophthalmology 1990;97:1689-98.
8. Stark WJ, Stulting RD, Bias WB, et al. The collaborative corneal transplantation studies (CCTS): effectiveness of histocompatibility matching in high-risk corneal transplantation. Arch Ophthalmol 1992;110:1392-403.

9. McGhee CN. Pharmacokinetics of ophthalmic corticosteroids. Br J Ophthalmol 1992;76:681-4.

10. Lam DSC, Wong AKK, Tham CoIY, Leigh ATS. The use of combined intravenous pulse methylprednisolone and oral cyclosporin A in the treatment of corneal graft rejection: a preliminary study. Eye 1998;12:615-8. 